\title{
The duality of schizotypy: is it both dimensional and categorical?
}

\section{Oliver John Mason*}

Research Department of Clinical, Educational and Health Psychology, University College London, London, UK *Correspondence: o.mason@ucl.ac.uk

Edited by:

Caroline Gurvich, Monash University, Australia

Susan Rossell, Swinburne University of Technology, Australia

Reviewed by:

Eduardo Fonseca-Pedrero, University of La Rioja, Spain

Keywords: schizotypy, taxon, dimensions, bibliometrics, psychometrics

Schizotypy is the notion that schizophrenia-like features can form, in the absence of illness, a temperamental "type" or personality trait. Both typological and characterological accounts were present at the notion's conception as, historically, both categorical ("Kraepelinian") and dimensional [e.g., Kretchmer's "schizothymic" temperament; (1)] accounts of psychotic illness have vied against one another with the former clearly ascendant in biological psychiatry at least. Paul Meehl's influential development of the categorical account (2) theorized the "schizotype" as the category as the fundamental phenotypic foundation of "true" schizophrenia. Variants of this model remain central to theorizing in the North American tradition at least. The dimensional view, revitalized by Hans Eysenck, is best represented in contemporary theory by Gordon Claridge's "quasi-dimensional" model (3).

In 1995, Adrian Raine and Todd Lencz (4) set out some of the theoretical and conceptual issues in schizotypal personality research and outlined the "categories versus dimensions" issue as "perhaps the most important" of all (p. 5). They suggested pursuing both approaches so as to see, which is most productive. There is of course a distinction here between theory and methodology. I aim to argue here based on four observations of the empirical literature that aspects of both theoretical accounts may be valid, and that a diversity of methods may have utility in the field.

Claridge's dimensional account postulates underlying dimensionality of risk for illness with superimposed clinical discontinuities - the schizophrenic "spectrum" of illnesses. The critical difference between the two accounts of schizotypy lies in the non-clinical portion of the phenotype. In the categorical account, only a portion of phenotypic schizotypy is at genuine elevated risk, the "true" schizotype, the remainder is pseudophenotypic, superficially mimicking schizotypy but not possessing true genetic risk: Adrian Raine (5) termed the latter "pseudo-schizotypal." In the dimensional account, by contrast, there is the possibility of "genuine" schizotypy possessing a healthy or adaptive outcome (6); a theme I reprise in my conclusions.

A few years ago (7), I conducted a bibliographic analysis of the schizotypy literature that evidenced the growing popularity of empirical research in the field (schizotyp ${ }^{*}$ OR schizoid ${ }^{\star}$ OR psychosis prone ${ }^{\star}$ ), and of experimental studies in particular. In addition, I divided the empirical literature into psychometric and experimental studies, and into those taking a categorical and dimensional approach (based on their statistical treatment). The major growth in the literature has been in experimental studies of which more have taken a dimensional (e.g., correlational) approach (Figure 1).

Clearly, there are advantages and disadvantages to both statistical approaches and this choice does not necessarily imply a strong theoretical preference. For example, most quantitative genetic studies examine correlations as a matter of course. Conversely, studies based on diagnostic procedures usually retain a categorical approach. Moreover, a minority of studies report both statistical treatments, often with broadly commensurate results. Treating schizotypy variables as continuous variables is perhaps sometimes preferred as statistical power in many analyses is likely to exceed dichotomized treatment. This is especially the case if the latter takes seriously the taxonomic prediction of $10-15 \%$ of a general population sample (arguably a "median split" is the worst of all possible worlds). Large samples are required if the truly taxonomic approach is to be taken in a multivariate analysis. While this suits some fields such as quantitative genetics, it is not suited to others such as brain imaging. On the other hand, a common strategy is to preselect "schizotypal" and "nonschizotypal" groups via large-scale screening using a psychometric instrument. This usefully reduces the number needed to test experimentally to achieve statistical power. However, the strategy may or may not imply testing of a categorical model - it is also, of course, a strategy of convenience for testing dimensional differences.

As a consequence of all these considerations, I would argue that while genuine differences clearly exist between the models theoretically, these are very rarely tested against one another genuinely at the empirical level. Evidence can be found (and is often rehearsed) for both categorical and dimensional positions - even from the same dataset. In some ways, this apparent duality may parallel the famous "waveparticle" duality of quantum theory that suggests that both accounts can be "true" in different ways, and thus seeks to explain a diverse range of observations. At the crudest level, one can observe that broad measurement of trait tendencies tend to produce continua, and narrow "symptomfocused" measures lead to categories. I would like to suggest some important ways that both may have validity and research 


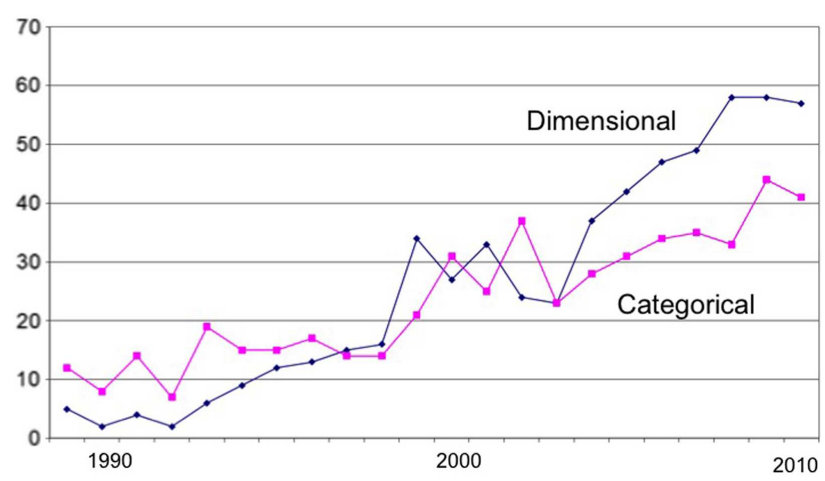

FIGURE 1 | Bibliometrics: dimensional and categorical approaches

utility (and I do not claim that this is an exhaustive list).

I am not alone in noticing empirical evidence for both positions (8). From reviews of the epidemiological evidence of clinical disorders, Linscott and van Os suggest that there is true continuum to the nonclinical. Where I differ from their position is their suggestion that evidence in the general population suggests a latent categorical structure with "two types of people." This structure is generally argued for as a result of attempts to identify a taxon psychometrically. However, the statistical issues of this argument certainly allow for divergent interpretations: the issue of taxonometrics in schizotypy has been much discussed with little resolution (e.g., see Personality and Individual Differences 44:8; 2008). Where I do agree with their position is in viewing schizotypy per se as too narrow a lens, "psychosis proneness" captures the variety of traits relevant to psychotic disorders as a whole.

\section{TRAIT MULTI-DIMENSIONALITY}

Regardless of psychometric arguments about putative taxons, it is likely that some measures suit one theoretical position better than another. Those with "stronger" symptom-like measures may tend to discontinuities, while others offer greater dimensionality. In addition, even the range and nature of dimensions of schizotypal personality are argued over, with perhaps the broadest consensus concerning a distinction between positive and negative schizotypy. Arguably, there are stronger indications for the taxonomic nature of negative schizotypal features such as trait anhedonia [for review see Ref. (9)]. Conversely, Edens et al. (10) found "compelling evidence in two studies of a latent dimensional structure to paranoid traits." In general, and perhaps somewhat surprisingly, there is better evidence for the continuous distribution of "positive" schizotypy (e.g., delusional/paranoid ideation and hallucination proneness) than for "negative" schizotypy (anhedonia/social impairment).

\section{THE POTENTIAL UTILITY OF SCHIZOTYPAL CLUSTERS}

In a development of this first point, Suhr and Spitznagel $(11,12)$ attempted to overcome the common inconsistency of neurocognitive findings in schizotypy by clustering schizotypal individuals rather than studying individual dimensions. Executive function deficits were selectively seen in the negative schizotypy cluster; who were also more often rated neurocognitively impaired. However, a cluster high on both positive and negative schizotypy had the most unusual social behavior ratings. Subsequently, Barrantes-Vidal et al. (13) similarly advanced evidence that clusters worked more effectively than dimensions in predicting neurocognition and neurological "soft signs." Arguably, the confluence of dimensional traits to produce a "taxon-like" cluster may be best suited to identifying those with neurocognitive deficits, and possibly also in other experimental contexts.

\section{THE OPERATION OF DISCONTINUOUS "STATE-LIKE" PHENOMENA}

While personality traits are usually seen as broadly consistent over time, stress or other unusual circumstances produce "state" effects that may possess qualitatively different, and thus discontinuous, features. In this way, traits may proceed, more or less temporarily, to "symptoms" in the absence of a diagnosed syndrome. Usually these are probably highly temporary, but where more persistent or frequent that they effectively form subsyndromal versions of disorders such as "basic symptoms" captured by the Schizophrenia Proneness Instrument (14). These sub-syndromal symptoms may be associated with the more clearly dysfunctional cognitive, affective, and behavioral features of schizotypy/schizophrenia. As they can become quite persistent states, they may well give the appearance of a taxon.

\section{EPISTATIC MECHANISMS MEDIATING GENE-ENVIRONIMENT INTERACTION}

It is increasingly accepted that many individual loci each make a very small contribution to overall genetic risk (15). On prima facie grounds, such evidence supports the notion of one or more continua $(16,17)$ and probably underpins the heritability seen for broadly defined schizotypal traits. However, there remains the possibility for individual schizotypal features to arise from more specific gene loci, or more likely from complex gene-gene and gene-environment interactions. Overall, it is difficult to disambiguate continuous from discontinuous genetic effects from studies of heritability alone. One of the largest heritability studies to date (18), albeit with no single standard psychometric scale, suggested a pattern of heritability for social anhedonia consistent with a single dominant gene as postulated in the Meehlian account. Overall, many heritability studies [e.g., Ref. (19)] postulate heritability of around 50\% with the remainder due to non-shared environmental variance. While the quest for a "schizophrenia gene" able to discriminate clinical from non-clinical groups continues with linkage and genome-wide association studies, there has been little sustained success: Weinberger concluded that results "are decidedly disappointing to those expecting this strategy to yield conclusive evidence of common variants predicting risk for schizophrenia" [p. 840, Ref. (20)]. A small number of gene-of-interest (GOI) studies have nevertheless some consistent results 
largely with positive schizotypy. These concern the polymorphisms of genes relevant to dopamine transmission such as COMT $(16,21)$, DRD1 and DRD2 (22), SLC6A3 (16, 21), or MAOA (16). Such studies evidence greater schizotypy associating with several polymorphisms such as rs4680 SNP (single nucleotide polymorphisms) within the COMT-gene in a continuous fashion. However, sometimes this association is only seen in the presence of an environmental factor such as childhood abuse (23). As investigation of these in detail is in its infancy, it is likely that much greater specification of their relevance and mode of action will occur in future studies.

There is also increasing evidence of epigenetic action, whereby environmental factors influence the expression of genes (15, 24). Svarkic et al. [p. 2, Ref. (25)] outline a model, whereby "abnormal epigenetic states with large effects are superimposed on a polygenic liability to schizophrenia." This is effectively an extension or variant of point 3 and highlights how the actions of specific genes (individually making a small quantitative contribution to risk) may translate into genuinely taxonomic discontinuities - but only in the context of a pathogenic environment.

\section{CONCLUSION}

Overall, I have attempted to argue that even in the non-pathological domain of schizotypal individual differences there are numerous possibilities for both dimensional and categorical expressions both of traits and states. Taxonomic expression has greater support for negative schizotypal features such as anhedonia and potentially some associated neurocognitive features; positive schizotypy, on the other hand, sees much empirical support for "true" dimensionality at both genotype and phenotypic expression. Even here, however, there is room for gene-environment interactions and epigenetics to produce discontinuous results.

As a rider to this final point, it is apposite to point out that there may equally be important phenotypic consequences for schizotypy in the absence of a pathogenic environment or the presence of a protective factor such as high cognitive or emotional intelligence. Thus, positive schizotypy is also associated with a range of "healthy" or at least adaptive outcomes. Again, paralleling the advantages seen with cluster analytic approaches, Tabak and Weisman de Mamani (26) identified several schizotypal latent profiles: the negative/disorganized schizotypy profile had the poorest levels of well-being and schizotypes solely with positive features had the highest-commensurate with non-schizotypes. Taking a similar latent profile analytic approach to a non-clinical sample, Hori et al. (27) described 15\% as "high-positive-schizotypy/adaptive" and possessing of high self-directedness, cooperativeness, and self-transcendence. This is consistent with growing evidence of the highly creative and spiritual outcomes for some schizotypal individuals $(28,29)$, and may point to the operation of antagonistic pleiotropy or genetic linkage such that schizotypal traits survived throughout our evolutionary history (30).

\section{REFERENCES}

1. Kretschmer E. Korerbau und Charakter. Berlin: Springer (1922).

2. Meehl PE. Schizotaxia, schizotypy, schizophrenia. Am Psychol (1962) 17(12):827. doi:10.1037/ h0041029

3. Claridge $\mathrm{G}$. The schizophrenias as nervous types. Br J Psychiatry (1972) 121:1-17. doi:10.1192/bjp. 121.1.1

4. Raine A, Lencz T. Conceptual and theoretical issues in schizotypal personality research. In: Raine A, Lencz T, Mednick SA, editors. Schizotypal Personality. Cambridge: Cambridge University Press (1995). p. 1-18.

5. Raine A. Schizotypal personality: neurodevelopmental and psychosocial trajectories. Annu Rev Clin Psychol (2006) 2:291-326. doi:10.1146/ annurev.clinpsy.2.022305.095318

6. McCreery C, Claridge G. Healthy schizotypy: the case of out-of-the-body experiences. Pers Individ Dif (2002) 32(1):141-54. doi:10.1016/S01918869(01)00013-7

7. Mason O. Schizotypy: a bibliometric analysis. Paper Presented at the Annual Meeting of the International Society for the Study of Individual Differences. London (2011).

8. Linscott RJ, van Os J. Systematic reviews of categorical versus continuum models in psychosis: evidence for discontinuous subpopulations underlying a psychometric continuum. Implications for DSM-V, DSM-VI, and DSM-VII. Annu Rev Clin Psychol (2010) 6:391-419. doi:10.1146/annurev. clinpsy.032408.153506

9. Kwapil TR, Gross GM, Chun CA, Silvia PJ, Barrantes-Vidal N. Anhedonia and negative symptom schizotypy. In: Ritsner M, editor. Anhedonia: A Comprehensive Handbook (Vol. II). Dordrecht: Springer (2014). p. 203-26.

10. Edens JF, Marcus DK, Morey LC. Paranoid personality has a dimensional latent structure: taxometric analyses of community and clinical samples.
J Abnorm Psychol (2009) 118(3):545. doi:10.1037/ a0016313

11. Suhr JA, Spitznagel MB. Factor versus cluster models of schizotypal traits. I: a comparison of unselected and highly schizotypal samples. Schizophr Res (2001) 52(3):231-9. doi:10.1016/S09209964(00)00170-5

12. Suhr JA, Spitznagel MB. Factor versus cluster models of schizotypal traits. II: relation to neuropsychological impairment. Schizophr Res (2001) 52(3):241-50. doi:10.1016/S0920-9964(00) 00185-7

13. Barrantes-Vidal N, Fañanás L, Rosa A, Caparrós B, Dolors Riba M, Obiols JE. Neurocognitive, behavioural and neurodevelopmental correlates of schizotypy clusters in adolescents from the general population. Schizophr Res (2003) 61(2):293-302. doi:10.1016/S0920-9964(02)00321-3

14. Schultze-Lutter F, Addington J, Ruhrmann S, Klosterkötter J. Schizophrenia Proneness Instrument, Adult Version (SPI-A). Rome: Giovanni Fioriti Editore srl (2007).

15. Plomin R, Haworth CMA, Davis OSP. Common disorders are quantitative traits. Nat Rev Genet (2009) 10:872-8. doi:10.1038/nrg2670

16. Grant P, Kuepper Y, Mueller EA, Wielpuetz C, Mason O, Hennig J. Dopaminergic foundations of schizotypy as measured by the German version of the Oxford-Liverpool Inventory of Feelings and Experiences (O-LIFE) - a suitable endophenotype of schizophrenia. Front Hum Neurosci (2013) 7:1. doi:10.3389/fnhum.2013.00001

17. Sieradzka D, Power RA, Freeman D, Cardno AG, McGuire P, Plomin R, et al. Are genetic risk factors for psychosis also associated with dimension-specific psychotic experiences in adolescence? PLoS One (2014) 9(4):e94398. doi:10. 1371/journal.pone.0094398

18. Hay DA, Martin NG, Foley D, Treloar SA, Kirk KM, Heath AC. Phenotypic and genetic analyses of a short measure of psychosis-proneness in a large-scale Australian twin study. Twin Res (2001) 4(01):30-40. doi:10.1375/twin.4.1.30

19. Linney YM, Murray RM, Peters ER, MacDonald AM, Rijsdijk F, Sham C. A quantitative genetic analysis of schizotypal personality traits. Psychol Med (2003) 33(5):803-16. doi:10.1017/ S0033291703007906

20. Weinberger DR, Egan MF, Bertolino A, Callicott JH, Mattay VS, Lipska BK, et al. Prefrontal neurons and the genetics of schizophrenia. Biol Psychiatry (2001) 50(11):825-44. doi:10.1016/S00063223(01)01252-5

21. Ettinger U, Joober R, De Guzman R, O’Driscoll GA. Schizotypy, attention deficit hyperactivity disorder, and dopamine genes. Psychiatry Clin Neurosci (2006) 60(6):764-7. doi:10.1111/j.14401819.2006.01594.x

22. Gurvich C, Louise S, Van Rheenen T, Neill E, Rossell S. The influence of prefrontal and striatal dopaminergic genes on cognitive control in high and low schizotypy. Biol Psychiatry (2013) 73(9):S270-270.

23. Savitz J, van der Merwe L, Newman TK, Stein DJ, Ramesar R. Catechol-o-methyltransferase genotype and childhood trauma may interact to impact schizotypal personality traits. Behav Genet (2010) 40(3):415-23. doi:10.1007/s10519009-9323-7 
24. Dempster EL, Pidsley R, Schalkwyk LC, Owens S, Georgiades A, Kane F, et al. Disease-associated epigenetic changes in monozygotic twins discordant for schizophrenia and bipolar disorder. Hum Mol Genet (2011) 20(24):4786-96. doi:10.1093/ $\mathrm{hmg} / \mathrm{ddr} 416$

25. Svrakic DM, Zorumski CF, Svrakic NM, Zwir I, Cloninger CR. Risk architecture of schizophrenia: the role of epigenetics. Curr Opin Psychiatry (2013) 26(2):188-95. doi:10.1097/YCO. 0b013e32835d 8329

26. Tabak NT, Weisman de Mamani AG. Latent profile analysis of healthy schizotypy within the extended psychosis phenotype. Psychiatry Res (2013) 210(3):1008-13. doi:10.1016/j.psychres. 2013.08.006

27. Hori H, Teraishi T, Sasayama D, Matsuo J, Kinoshita Y, Ota M, et al. A latent profile analysis of schizotypy, temperament and character in a nonclinical population: association with neurocognition. J Psychiatr Res (2014) 48(1):56-64. doi:10.1016/j.jpsychires.2013.10.006

28. Nelson B, Rawlings D. Relating schizotypy and personality to the phenomenology of creativity. Schizophr Bull (2010) 36(2):388-99. doi:10.1093/ schbul/sbn098

29. Farias M, Underwood R, Claridge G. Unusual but sound minds: mental health indicators in spiritual individuals. Br J Psychol (2013) 104(3):364-81. doi:10.1111/j.2044-8295.2012.02128.x

30. Crespi B, Summers K, Dorus S. Adaptive evolution of genes underlying schizophrenia. Proc R Soc B Biol Sci (2007) 274(1627):2801-10. doi:10.1098/ rspb.2007.0876

Conflict of Interest Statement: The author declares that the research was conducted in the absence of any commercial or financial relationships that could be construed as a potential conflict of interest.

Received: 13 June 2014; accepted: 11 September 2014; published online: 24 September 2014.

Citation: Mason OJ (2014) The duality of schizotypy: is it both dimensional and categorical? Front. Psychiatry 5:134. doi: 10.3389/fpsyt.2014.00134

This article was submitted to Schizophrenia, a section of the journal Frontiers in Psychiatry.

Copyright (c) 2014 Mason. This is an open-access article distributed under the terms of the Creative Commons Attribution License (CC BY). The use, distribution or reproduction in other forums is permitted, provided the original author(s) or licensor are credited and that the original publication in this journal is cited, in accordance with accepted academic practice. No use, distribution or reproduction is permitted which does not comply with these terms. 